\title{
Physical, mechanical and thermal properties of Crushed Sand Concrete containing Rubber Waste
}

\author{
Guendouz Mohamed $^{1}$, Boukhelkhal Djamila ${ }^{1}$ \\ ${ }^{1}$ LME Laboratory, University of Medea, Algeria
}

\begin{abstract}
Over the past twenty years, the rubber wastes are an important part of municipal solid waste. This work focuses on the recycling of rubber waste, specifically rubber waste of used shoes discharged into the nature and added in the mass of crushed sand concrete with percentage $(10 \%, 20 \%, 30 \%$ and $40 \%)$. The physical (workability, fresh density), mechanical (compressive and flexural strength) and thermal (thermal conductivity) of different crushed sand concrete made are analyzed and compared to the respective controls. The use of rubber waste in crushed sand concrete contributes to reduce the bulk density and performance of sand concrete. Nevertheless, the use of rubber aggregate leads to a significant reduction in thermal conductivity, which improves the thermal insulation of crushed sand concrete.
\end{abstract}

\section{Introduction}

Rubber waste management is one of the serious environmental problems in the world and it has many challenges for the recycling process. The recycling and disposing of some waste rubber types have many challenges. These are attributed to the difficulty of making separation, type of rubber used, incineration problems, environmental regulations, and increasing the cost of recycling. Use of such waste rubber materials in civil and construction engineering applications has become an attractive alternative to disposal to reduce both the cost of disposal and waste quantities. Many authors [1-9] have reported the properties of concrete with used tyre rubbers and plastics waste. Their results indicate that the size, proportion, and surface texture of rubber particles affect the strength of used tyre rubber contained in concrete [1-9].Eldin and Senouci [3] conducted experiments to examine the strength and toughness properties of concrete made with rubber waste. They noted that the mechanical strength decrease when the rubber waste content increase. Several authors [1,3,4] used tyre chipped rubber containing Portland cement concrete for uses in sound/crash barriers, retaining structures, and pavement structures has been extensively studied. Test results founded that the use of used tyre chipped rubber considerably increases toughness and resistance. Khatib and Bayomy [1] studied the influence of adding two rubbers, crumb and chipped on performances of concrete. They found that the compressive strength of concrete would decrease with increasing rubber content.

This work aims to study the possibility of using waste rubber of shoes in sand concrete without any transformation except grinding, to minimize the cost of the final material. The influence of the proportion of waste used on the physical, mechanical and thermal properties of the new material has been studied and analyzed.

\section{Experimental}

\subsection{Materials}

The used sand in this work was extracted from the south of Algeria, near the city of BOUIRA. The particle size distribution is shown in Figure 1, and the physical properties are presented in Table 1. The X-ray Diffraction analysis of used sand demonstrates their essentially limestone nature "Figure 2".A SEM investigation reveals the crusaded shape of the grains "Figure 3".

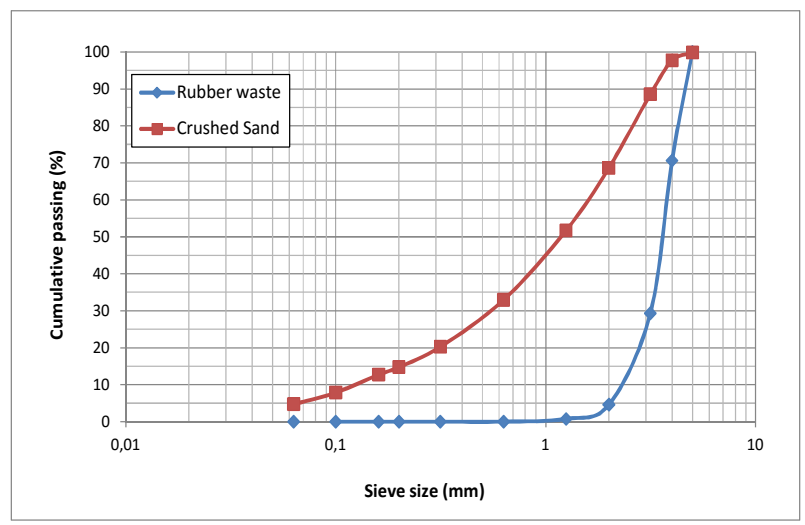

Fig. 1. Particle size distribution of used sand and rubber waste. 
Table 1. Physical properties of used sand.

\begin{tabular}{|c|c|c|}
\hline Properties & Sand & Norm \\
\hline Apparent density $\left(\mathrm{kg} / \mathrm{m}^{3}\right)$ & 1490 & NP EN 1097-3 \\
\hline Specific density $\left(\mathrm{kg} / \mathrm{m}^{3}\right)$ & 2500 & NP EN 1097-6 \\
\hline Water absorption (\%) & 1.5 & NP EN 1097-6 \\
\hline Sand equivalent (\%) & 63.50 & NP EN 933-8 \\
\hline Fineness modulus & 3.14 & NP EN 933-1 \\
\hline Compactness (\%) & 0.60 & NF P 18-555 \\
\hline Porosity (\%) & 0.40 & NF P 18-555 \\
\hline
\end{tabular}

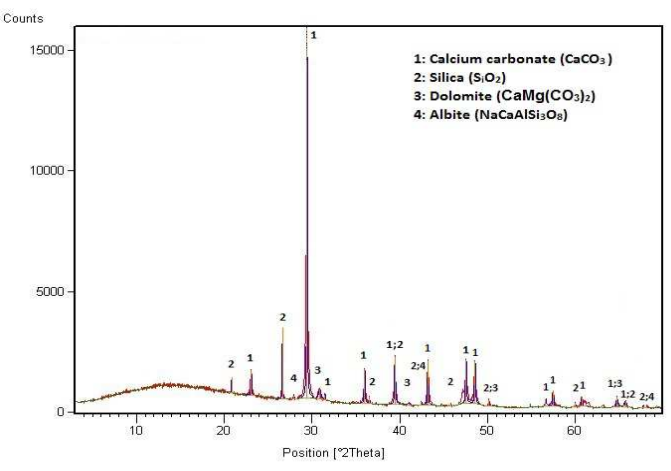

Fig. 2. X-ray diffractogram analysis of used crushed sand.

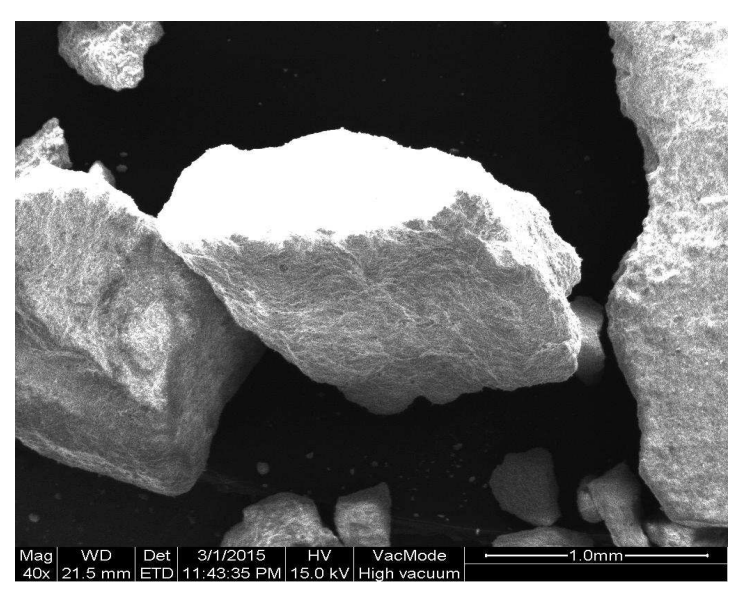

Fig. 3. Scanning electron micrographs of used crushed sand.

Portland cement CEM II/A 42.5 from CHLEF Factory in Algeria was used throughout this study, with a density of $3100 \mathrm{~kg} / \mathrm{m}^{3}$. Moreover, the chemical analysis revealed the existence of the chemical products shown in Fig. 3 with the proportions presented in Table 2.
Table 2. The chemical composition of used cement (\%).

\begin{tabular}{|c|c|}
\hline Materials Oxides & Cement \\
\hline $\mathrm{SiO}_{2}$ & 21.89 \\
\hline $\mathrm{Al}_{2} \mathrm{O}_{3}$ & 6.15 \\
\hline $\mathrm{Fe}_{2} \mathrm{O}_{3}$ & 3.95 \\
\hline $\mathrm{CaO}$ & 58.76 \\
\hline $\mathrm{MgO}$ & 1.13 \\
\hline $\mathrm{K}_{2} \mathrm{O}$ & 0.67 \\
\hline $\mathrm{Na}_{2} \mathrm{O}$ & 0.57 \\
\hline $\mathrm{SO}_{3}$ & 1.62 \\
\hline $\mathrm{CaO}_{\text {Free }}$ & 0.45 \\
\hline $\mathrm{P} . \mathrm{F}$ & 4.67 \\
\hline Total & 99.86 \\
\hline
\end{tabular}

The use of fillers in sand concrete composition is essential [10]. Their use is intended to complete the grading curve of sand in its finest part in order to obtain more compact concrete and reduce the cement content and therefore the cost of concrete [11]. In this work the fillers used are the limestone powder. Their specific density is $2,857 \mathrm{~kg} / \mathrm{m}^{3}$, and specific surface area 310 $\mathrm{m}^{2} / \mathrm{kg}$.

The rubber waste used in this work to obtain by the recycling the waste of shoes discharged into the environment after were collected, are washed, compressed, crushed and extruded in the form of grains, and added in the mass of sand concrete with percentage $10 \%, 20 \%, 30 \%$ and $40 \%$. Figure 4 shows the general aspect of used rubber waste in this work. The sieve analysis results are given in Figure 1 and the table 3 lists the set of physical, mechanical properties.
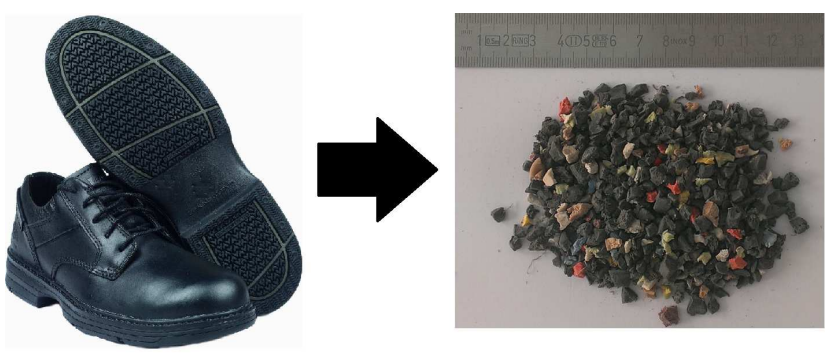

Fig.4. General aspect of used rubber waste.

Table 3. Physical and thermal properties of used rubber wastes.

\begin{tabular}{|c|c|}
\hline Properties & Rubber waste \\
\hline Diameter & 1.5 \\
\hline Apparent density $\left(\mathrm{kg} / \mathrm{m}^{3}\right)$ & 0.8 \\
\hline Bulk density $\left(\mathrm{kg} / \mathrm{m}^{3}\right)$ & 1.28 \\
\hline Compactness $(\%)$ & 62.5 \\
\hline Porosity $(\%)$ & 37.5 \\
\hline Water absorption $(\%)$ & 0.1 \\
\hline Thermal conductivity $(\mathrm{W} / \mathrm{m} \mathrm{K})$ & 0.15 \\
\hline
\end{tabular}


The admixture used is an Algerian plasticiser of 'MEDAFLUID 104', liquid form; color chestnut; a PH equal to 6 , density $1,04 \pm 0,01$ and a content of chlore < $1 \mathrm{~g} / \mathrm{L}$.

The mixing water used for the different mixes is the distribution drinking water.

\subsection{Mix design}

The optimal compositions of the sand concrete studied, without rubber waste, is based on the experimental method of project of Sablocrete [11]. This gave for cement proportioning of $350 \mathrm{~kg} / \mathrm{m}^{3}, 1560 \mathrm{~kg} / \mathrm{m}^{3}$ of sand, $130 \mathrm{~kg} / \mathrm{m}^{3}$ of fillers, and a water/cement ratio of 0.75 , a percentage of plasticiser of $1 \%$ of weight of cement. The rubber waste is added in sand concrete at dosages $(0 \%, 10 \%, 20 \%, 30 \%$ and $40 \%)$. Literary codes identify each mixture in a precise way:

- CSC: Control sand concrete (without rubber).

- SCRW: Sand concrete with rubber waste.

The specimens produced were cured in air at $20^{\circ} \mathrm{C}$ and $50 \% \mathrm{RH}$. After $24 \mathrm{~h}$, they were removed from the molds and placed in water for another $24 \mathrm{~h}$ and then open-air stored until the day of testing. Such curing has been chosen according the normal manufacturing of sand concrete in Algeria. This procedure was respected for all compositions and all tests.

\subsection{Tests Procedures}

The fresh crushed sand concrete was characterized in what concerns its slump, determined by means of the Abrams cone test (NF P 18-451), and fresh density (EN 12350-6). Flexural strength was determined (using three points) for each composition on three $4 \times 4 \times 16 \mathrm{~cm}$ prismatic samples. The half-samples resulting from this test were then submitted to compression on a $4 \times 4 \mathrm{~cm}$ test section (EN 196-1). Sample size is significant in comparison with the size of aggregates.

The measurements of thermal conductivity led to the determination of the following parameters: thermal conductivity $(\mathrm{k})$, on three $40 \times 80 \times 160 \mathrm{~mm}$ samples using a CT-Meter machine "Figure 5".

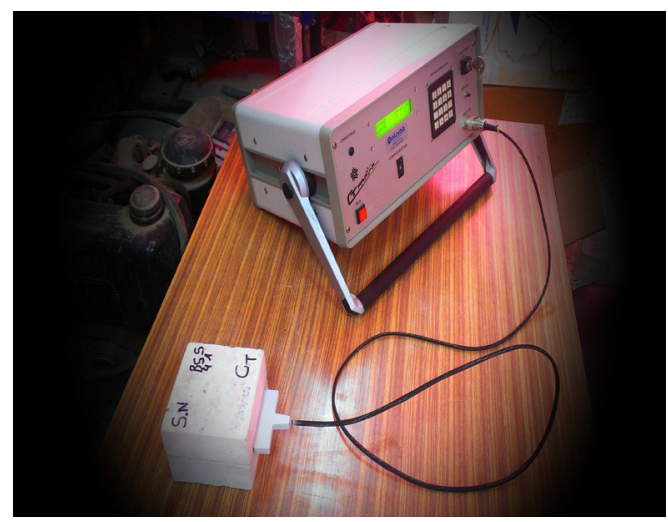

Fig. 5. Measurement of thermal properties.

\section{Results and discussion}

\subsection{Workability}

Figure 6 give the slump of crushed sand concrete as a function of rubber waste. The slump of sand concrete as a function the content difference of rubber waste is sowed in Figure 3. The use of rubber waste as addition in sand concrete contributes to increase the slump of sand concrete, probably due to the to the presence of more free water in the mixes containing rubber, because the rubber aggregate cannot absorb water during mixing. Several authors [1] reported that the use of rubber waste in the concrete, involves a significant reduction in the workability.In order to limit the number of compositions and to be able to compare them on a common basis, it has been decided to carry out the research project at a constant workability (slump between $70 \mathrm{~mm}$ and $90 \mathrm{~mm}$ ) by the addition of the quantity of admixture for each mixture contains coffee waste.

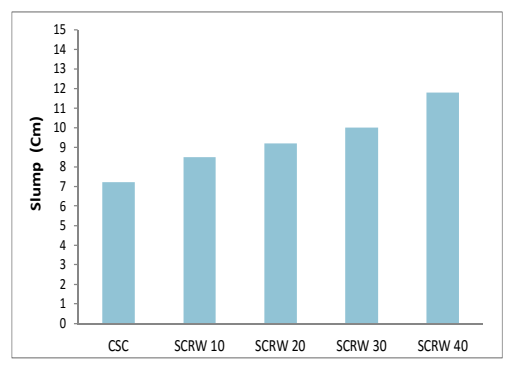

Fig.6.Slump of crushed sand concrete as function of rubber waste content.

\subsection{Bulk density}

Figure 7 give the bulk density of crushed sand concrete as a function of rubber waste. The results displayed that the incorporation of rubber waste in crushed sand concrete contributes to reduce the bulk density. This reduction probably due to the lower density of the rubber compared with the dune sand and the air content caused by the grain of RW, which in turn reduces the unit weight of the mixtures.Khatib and Bayomy [1] concluded that because of low specific gravity of rubber particles, unit weight of mixtures containing rubber decreases with the increase in the percentage of rubber content. 


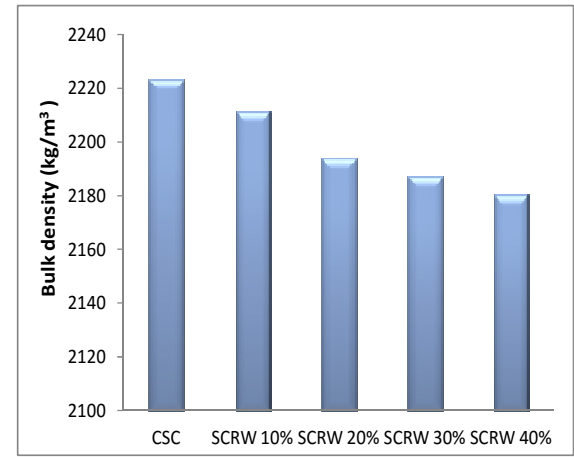

Fig.7 Bulk density of crushed sand concrete as function of spent rubber waste content.

\subsection{Mechanical strength}

The compressive and flexural strength tests of hardened crushed sand concrete were performed at the age of 28 are showed in figure 8 and 9 . The results displayed in that compressive strengths of crushed sand concrete decrease $20 \%$ respectively for addition of $40 \%$ natural crushed sand by rubber waste. Even thing in the case of the flexural strengths, which indicates that the addition of $40 \%$ of the rubber waste in a crushed sand concrete represents decrease the performances of new materials. This trend may be related a poor adhesion between the surface of the rubber aggregate and binder paste is likely to have contributed to such a strong decay of mechanical properties. This reduction in performance of SC can be also caused by the great porosity and hardness of grain of rubber waste compared with natural crushed sand. Several authors [3] reported that the addition of rubber waste in the concrete, involves a significant reduction in the mechanical strength of concrete.

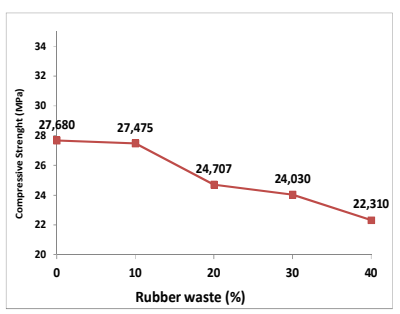

Fig.8. Compressive strength of crushed sand concrete as function of rubber waste content.

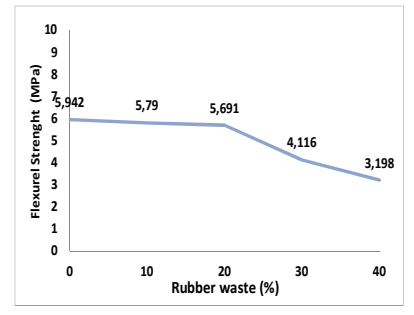

Fig.9 Flexurel strength of crushed sand concrete as function of rubber waste content.

\subsection{Thermal properties}

The thermal conductivity values of the specimens measured at 28 days are showed in figure 10 . The results show that the thermal conductivity of crushed sand concrete decrease when the percentage of addition of rubber waste increase. It is thought that, this situation caused by the lower TC coefficient of the rubber $(0.15$ $\mathrm{W} / \mathrm{m} \mathrm{K})$ than natural aggregate $(2 \mathrm{~W} / \mathrm{m} \mathrm{K})$ [12]. So the decreasing thermal conductivity came also from the increase in porosity induced by the rubber waste. In fact the pores contain air which has a TC $(0.024 \mathrm{~W} / \mathrm{mK})$ much lower than all the other components of the SC. Similar results were observed by several authors in composite systems, for example F. Iucolano et al. [13] in a study on plastic waste in mortar composites, and it's showed a decreased in value of thermal conductivity of mortar containing PET about $50 \%$ lower than a traditional mortar.

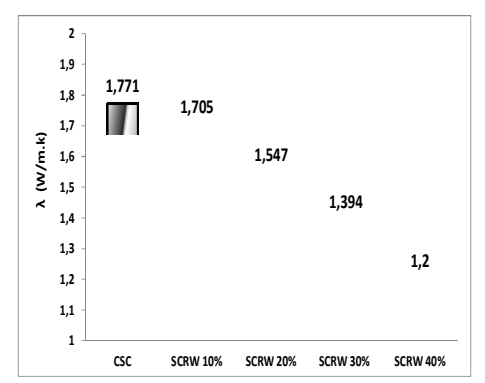

Fig.10. Thermal Conductivity of crushed sand concrete as function of rubber waste content. 


\section{Conclusions}

The results which could be summarized and concluded as:

1- The workability of crushed sand concrete increase when the addition of rubber shoes wastes increase.

2- There is a reduction in the bulk density of crushed sand concrete as the content of rubber waste increases.

3- The compressive and flexural strength values of crushed SC mixtures tend to decrease above the values for the reference SC with increasing the waste rubber ratio. But this result was acceptable for lightweight concrete

4- Rubber waste addition in sand concrete caused a reduction $(34 \%)$ in the values of thermal conductivity of the sand concrete.

Finally, the use of rubber waste of shoes as aggregates in crushed sand concrete can most of the problems associated with their disposal as well as save natural resources related to aggregates mining.

\section{References}

1. ZK . Khatib, FM. Bayomy, ASCE J Mater Civil Eng. 11 (1999),206-13

2. D. Fedroff, S. Ahmad , BZ. Savas, Washington, DC: Transportation Research Board. (1996).

3. NN. Eldin., AB. Senouci. ASCE J Mater Civil Eng. (1993),478-96.

4. NA. Ali, AD. Amos., M. Roberts, Scotland (UK): University of Dundee. (2000).

5. Rostami H., Lepore J., Silverstraim T., Zundi I. Scotland (UK): University of Dundee (2000).

6. IB . Topcu, Cem Concr Res.25 (1995) (2):304-10.

7. NI. Fattuhi, NA. Clark. J Construct Build Mater. (1996).229-36.

8. M. Guendouz ,F. Debieb ,O. Boukendakdji,E.H. Kadri, M. Bentchikou and H. Soualhi.J Mater and Env Scien, J. Mater. Environ. Sci. 4 (2013) $227-$ 232.7 (2).(2016),p.382-389.

9. M. Guendouz., F. Debieb and E.H. Kadri. 33èmes Rencontres de l'AUGC, ISABTP/UPPA, Anglet, 27 au 29 mai 2015 Bayonne, France, (2015),p 1-8.

10. AFNOR. Concrete - Sand concrete. Projet P 18-500. (1994).

11. Presse de l'Ecole Nationale des Ponts et Chaussées. 'Béton de sable: Caractéristiques et pratique d'utilisation'. (Projet SABLOCRETE) édition. (1994)

12. K. Hannawi ,S. Kamali-Bernard, W. Prince , J.Waste Manage.30 (2010).2312-20.

13. F. Iucolano ,B. Liguori ,D. Caputo ,F. Colangelo , R. Cioffi , Mater and Desi. 52(2013). 916-922. 